\title{
A novel liquid/liquid extraction process composed of surfactant and acetonitrile for purification of polygalacturonase enzyme from Durio zibethinus
}

\begin{abstract}
Polygalacturonase is one of the important enzymes used in various industries such as food, detergent, pharmaceutical, textile, pulp and paper. A novel liquid/liquid extraction process composed of surfactant and acetonitrile was employed for the first time to purify polygalacturonase from Durio zibethinus. The influences of different parameters such as type and concentration of surfactants, concentrations of acetonitrile and composition of surfactant/acetonitrile on partitioning behavior and recovery of polygalacturonase was investigated. Moreover, the effect of $\mathrm{pH}$ of system and crude load on purification fold and yield of purified polygalacturonase were studied. The results of the experiment indicated the polygalacturonase was partitioned into surfactant top rich phase with impurities being partitioned into acetonitrile bottom rich phase in the novel method of liquid/liquid process composed of $23 \%(\mathrm{w} / \mathrm{w})$ Triton X-100 and $19 \%(\mathrm{w} / \mathrm{w})$ acetonitrile, at $55.6 \%$ of TLL (tie line length) crude load of $25 \%(\mathrm{w} / \mathrm{w})$ at $\mathrm{pH}$ 6.0. Recovery and recycling of components also was measured in each successive step of liquid/liquid extraction process. The enzyme was successfully recovered by the method with a high purification factor of 14.3 and yield of 97.3\% while phase components were also recovered and recycled above 95\%. This study demonstrated that the novel method of liquid/liquid extraction process can be used as an efficient and economical extraction method rather than the traditional methods of extraction for the purification and recovery of the valuable enzyme.
\end{abstract}

Keywords: Remote sensing; Spectroradiometer; Band selection; Asphalt road extraction; WorldView-2; Spectral index 